\title{
Funding an undergraduate microcomputer laboratory: A case study
}

\author{
HUNTER A. MCALLISTER \\ Southeastern Louisiana University, Hammond, Louisiana
}

\begin{abstract}
A National Science Foundation grant was used to fund a microcomputer laboratory for teaching research skills. Issues relating to the grant process are discussed. Also discussed are hardware and software selections, administrative and physical structure of the lab, and the implementation in both introductory and advanced courses.
\end{abstract}

After attending an APA Convention workshop on the use of microcomputers in undergraduate psychology courses, I was thoroughly convinced that our psychology program at Southeastern Louisiana University could reap tremendous benefits by setting up its own computerized instructional laboratory. With what I had learned at the workshop and from talking with others who had set up laboratories, I knew the type of equipment and software needed, what the physical layout of the lab should be, and many other details that go into setting up a computer lab. In fact, there was only one issue that I didn't have an answer for: Where was the money for all this going to come from? My search for funds ended when I discovered the College Science Instrumentation Program of the National Science Foundation (NSF). It was an almost ideal match for our needs: Its eligible activities clearly included the use of computers in teaching undergraduate research, it was aimed at primarily undergraduate institutions, and it would provide up to $\$ 50,000$ in matching funds.

\section{Departmental Background}

Before discussing the NSF grant, some background on the department is necessary. The undergraduate program in psychology at Southeastern Louisiana University heavily emphasizes research. We believe that, although many of the "facts" taught today may turn out to be wrong, the process of discovering these facts remains relatively constant. Thus, an understanding of the research process is considered the most important knowledge that students can gain from our program. From the very first course that students take, this research emphasis is obvious. The instructors in the introductory psychology course spend the first 1 to $1 \frac{1 / 2}{2}$ weeks of the course on methods. In addition to the class time, students are required to spend from 3-5 h outside of class in some research activity (e.g., participating as subjects, attending research seminars, etc.).

Further evidence of our commitment to having students understand the research process can be seen in the psychology curriculum. Psychology majors are required to

Correspondence concerning this article may be sent to Hunter A. McAllister, Department of Psychology, P. O. Box 665, University Station, Hammond, LA 70402. take three courses directly concerned with the research process; a fourth course is strongly recommended. The research sequence begins with psychological statistics, in which students are taught both descriptive and inferential statistics. The next course in the sequence is a 4-h course dealing with experimental design. The course consists of $2 \mathrm{~h}$ of lecture and $2 \mathrm{~h}$ of lab each week. Following the statistics and design courses, there is a course in which the student applies the research skills learned in the two previous courses. As part of a research team, the student conducts a piece of original research designed by a faculty member. The students collect and analyze this "real" data, then write a report on the project in APA format. Finally, each student who elects to take the independent research course works individually with a faculty member and is allowed a much more active part in the selection of the research topic and design.

\section{Writing the Grant}

In my first attempt to obtain a grant, I focused on what a computer lab would do for the four research courses. First, I described how several software packages could be used to provide more meaningful laboratory experiences in the design course. These packages would allow students to run subjects (or themselves) in some of the most significant studies in psychology. The data could be stored in a common class data file, allowing them to compare their own results, individually and as a class, with results reported in the literature. I then went on to describe how the computers could be used as research instruments in the more advanced research courses. Computers could provide the precise timing and control of stimulus material needed in such areas as cognitive psychology, learning/memory, and sensation/perception. If I had stopped at this point I might well have received the grant; however, I went on to describe other uses. For example, I pointed out that there were computer-aided instruction (CAI) packages that would allow us to teach some of the more difficult concepts in statistics. We proposed to use programs, such as STATMASTER, that would allow the student to explore statistical concepts by asking "what if" types of questions. In addition to such CAI usage, I mentioned that the computers also could be 
used by the students to write their research papers with word-processing programs.

This first grant was not funded. I received a rather formal rejection notice from NSF, along with the reviews and an informal note from the NSF project director. In this informal note, I was told that the proposal was rejected mainly because of the references to CAI and word processing. The program could only support computers for use as scientific instruments, and these other uses hurt the proposal. I was encouraged to revise the proposal and resubmit the next year. Given the rather positive reviews and the note from the project director, I set about revising the proposal.

In the second grant proposal, I made two major changes. First, following the vertical integration ideas of Castellan (1984), I described how the research software packages could be used with students in introductory psychology and with students in the more advanced classes. For example, students in the introductory course could be run as subjects by a computer program and, in the process, gain a general understanding of the nature of research in that area. Later on, in a more advanced course, they might use the software again, but this time exploring some of the more subtle aspects of the phenomenon by changing some of the parameters and observing the effects. Furthermore, in a statistics or design course, the program could be used to collect data for analysis; the emphasis here being more on the design and statistics than on the phenomenon itself. The second major change in the grant was to delete the discussions of CAI and word processing. Although these changes may not seem major, they resulted in almost doubling the size of the grant. The inclusion of the introductory students meant that the number of computers and copies of software programs would have to be increased. Thus, the second grant was for almost $\$ 40,000$, whereas the first had been for $\$ 21,000$. This second grant was approved for funding.

Several conclusions can be drawn from the above description of the process of obtaining an NSF equipment grant. First, pay very close attention to what is and what is not an acceptable activity for the grant. In my first grant, in an attempt to show how far-reaching a computer lab would be, I undermined the main thrust of the grant by bringing in side issues, such as word processing and CAI. Second, don't be discouraged if your first attempt is not successful. The comments by the reviewers and the program director are detailed enough to enable you to make meaningful revisions in a resubmission. And finally, don't scale down your grant because you think that if you ask for less money you will have a greater chance of having your university and NSF accept the grant. It was my experience that the amount of money involved was never that crucial an issue. The fact that my second grant was for twice the amount of my first grant did not seriously concern my university or NSF.

\section{Implementing the Grant-The Equipment}

I had proposed that our computer lab be outfitted with Apple Ile computers. The choice of Apple computers was dictated by the clear superiority of the software available for these machines over that available for other machines (e.g., the IBM PC). To purchase the equipment, I had to clear the order with the computer services department. Computer services was not in favor of the purchase of Apple Ile computers. They argued that the IBM PC was a technically superior machine and that more and more software was being designed for the PC than was being designed for the Apple Ile. They also pointed out that IBM was dropping its PC prices down into the range of the IIe. Finally, they informed me that they were not as well equipped to provide maintenance for Apples as they were for IBMs. To placate computer services, I began to call the software companies to discuss their plans for the PC. Two of the major software providers, Conduit and Life Science, informed me that most of their software would soon be available for the PC.

It became obvious to me that our new computer lab should be made up of IBM PCs, but how would NSF react to a change of equipment? Given my past experiences with bureaucracy, I was certain that such a radical change in the proposal would require a tremendous amount of written justification that would take months to be reviewed and even then perhaps not be approved. With much trepidation, I called the NSF project director and briefly described the hardware changes that I wanted to make. I could hardly believe it when he said to go ahead with the changes. I inquired whether I would need written approval and he told me that I wouldn't. I was told to simply put together the best psychology computer lab that I could for the money. If I found equipment that was technically better or was at a better price than what I had proposed, then I should go ahead and order it. The same was true of software. If I discovered something that was better than what I had proposed, I shouldn't feel tied to the original proposal. Not until the lab was finished and I wrote my final report would I have to describe the various substitutions that I made. Given the rapid changes in the world of scientific instruments, particularly computers, this is a most reasonable way to run the program. I have no doubt that this flexible policy has enabled me to develop a lab far superior to the one I had originally proposed.

Obtaining the money from NSF to pay for the equipment was much simpler than I had anticipated. They made the funds immediately available to the university in a lump sum, and I simply drew the funds for my various purchases from a university budget, following the same procedures that I would use for our normal departmental purchases.

In summary, NSF has made the administering of an equipment grant as simple as it could possibly be. Faculty should not hesitate to write a grant for fear of getting lost in a bureaucratic jungle of red tape.

\section{Setting Up the Lab}

Southeastern Louisiana University committed to much more than simple matching when all the costs are considered. For example, a one-course release for the lab direc- 
tor was written into the proposal. There also were expenses for maintenance written into the grant. However, this was only the beginning. Once the process of physically setting up the lab began, other expenses were incurred. The room in which most of the computers were to be housed had to be rewired to accommodate the power demands of the computers and printers. Two window-unit air conditioners were added to handle the heat that was generated by the equipment and the equipment users. Security systems had to be installed to protect the university's investment. Cubicles to hold the computers and printers had to be constructed. New locks had to be installed. Many of these expenses had not been anticipated, and although none of these expenses were allowed to count as matching funds, the university willingly covered them.

One as-yet-unmentioned feature of the NSF grant is the leverage it provides. Under normal circumstances it would have taken at least a full semester for the lab to be completed, but, by stressing the importance of getting the NSF project functioning, the lab was completed in a matter of weeks. So, not only were all the laboratory costs covered, but also the work was done very quickly.

\section{Administrative Structure of the Lab}

As pointed out by Castellan (1986), one of the most important aspects of an effective lab is for it to be adequately staffed. There are three basic jobs that have to be filled: (1) monitoring the lab, (2) maintenance, and (3) coordination. Our lab is monitored by a trained undergraduate or graduate student for approximately $25 \mathrm{~h}$ each week. Each monitor goes through a 3 -week training period in which he/she learns basic information about the care and use of the hardware and becomes familiar with each piece of software in the lab. Monitors also are introduced to the spreadsheet program (Lotus 1-2-3) that we use for keeping track of every student that uses the lab. The monitors are responsible for the day-in and day-out functioning of the lab. They instruct students in the use of the various programs and are there to handle any problems that crop up. They also keep the lab in order, handle student records so that instructors can be kept abreast of their students' computer usage, and handle minor hardware and software problems. The maintenance of these computers and all microcomputers on campus is handled by the computer services department. They do all of our major maintenance (anything from cleaning a disk drive to replacing a motherboard). Finally, we have a faculty director who is responsible for overseeing the lab. I have been given a one-course release each semester to handle this job. As Castellan (1986) stressed, and I fully agree, having a lab director is absolutely essential. Student monitors come and go; a lab director provides for the continuity of lab functioning. Perhaps the most important function that the director can fill is the coordinating of the software and hardware needs of the department. Since we are attempting to integrate the use of computers throughout our curriculum, virtually every member of our faculty will be using the computers in at least some of their courses. Without someone to coordinate the activities, there is a real danger that unnecessary hardware and software will be purchased.

\section{Physical Arrangement of the Lab}

There are two philosophies in the physical structuring of a computer lab. According to some, the best physical arrangement is to have all the computers located in one large lab (Castellan, 1986). Such an arrangement makes it easier to monitor usage and facilitates the computers' use for instructional purposes. However, others argue the privacy and ease of concentration that small private rooms provide outweigh the advantages of a central arrangement (Hornby \& Anderson, 1988). We compromised by having both kinds of labs. We have 14 computers and three printers in one large room where our introductory psychology students work on the simulation programs. It is also possible for a faculty member to schedule the entire room for one of his/her classes. This room is monitored by a trained student worker throughout the day. Our other computers are in small private rooms. These rooms are used primarily for student research projects requiring privacy for the individual subject (e.g., experiments that involve auditory stimuli that would be distracting to other subjects).

\section{Implementation in Introductory Psychology}

We selected two packages of programs designed for introductory students: Discovering Psychology (Levy, Grant, Morgan, \& Yunker, 1985) and Simlabs (Queen's University Psychology Department, 1986). Both packages allowed students to participate as subjects in simulation experiments. Our experience with these two packages was very similar to that of Hornby and Anderson (1988). The packages were somewhat weak in connecting the experience of a subject with the content material covered in class. In keeping with the suggestions of Hornby and Anderson (1988), we have culled the set of experiments down to a set that best fits our introductory course, and, for this subset of programs, we are developing our own supplemental material to better connect the simulations with the classroom.

In spite of the above difficulty, the students have responded well to the programs. The computer lab is but one method that students can use for fulfilling the course requirement for outside activities; however, it is by far the most popular. The sign-up sheets for computer times are filled almost as soon as they are posted. As for whether the computers are making our students more sophisticated in research, we really don't have the answer as yet. At an informal level, reports from both students and faculty are very positive; however, we have not conducted a more formal evaluation. Once we have completed the supplemental material, we plan to formally evaluate the impact of the computer lab experience for the introductory student. 
Implementation in the

\section{Experimental Design Course}

In the original conception of the lab, the intention was to let students in the design course use some of the experiment simulation programs to collect real data from the introductory students. The design students could manipulate some of the parameters of the program and look at the effects on the introductory students' performance. Ideally, each class member would have run several subjects, and the results would be pooled for the data analysis. Unfortunately, we ran into many of the same problems discussed by Eamon (1986). Either the programs were not made for pooling data from several disks or, if they did allow pooling, the data could not be read by statistical packages. In addition, there was the problem of available research topics. Although the programs did allow for replicating many of the classic procedures in such areas as learning/memory, sensation/perception, and cognitive psychology, the topics and methods were not what the teacher in the course was most interested in. Fortunately, the instructor of the class, who was expert in programming Turbo Pascal, constructed his own software. By modifying programs that had been used in some of his own research, he designed programs that would present the stimulus information, perform various control features (e.g., counterbalancing), collect the data, and then feed the data into a statistical program for data analysis. The class worked on some extensions of the research that had been conducted by the teacher. The computers allowed the data to be collected very rapidly, and the class had more than the usual amount of time for data analysis and discussion of the results.

As for whether the computers enhanced the teaching of this course, again, as of yet there has been no formal evaluation. However, the course evaluations and the grades were the highest ever for this course. Both student and faculty comments about the lab also were very positive. How much of the improvement is real and how much is a Hawthorne effect is yet to be determined.

\section{Implementation in the Research Course}

In the research course, students were not expected to use the commercially packaged software. Since all of the faculty that teach this research course are themselves involved in research using the computer, the student projects were expected to be extensions of this faculty research. This is, in fact, the way that the class has operated. All sections of the course that have been taught since the computers' arrival have used the computers for the group projects. For the first time, we had enough computers for the students to be involved in the same research areas as were the faculty. No longer did projects have to be dreamed up to fit the limitations of our student equipment. Now students could work on research projects that the faculty were truly excited about. This excitement spread to the students, who became very ego-involved in the outcome of the research. Some of the groups voluntarily ran almost twice the number of required hours in order to explore further intriguing find- ings. This greater involvement with the project also showed up in the amount of time and effort on the research reports, which were clearly superior to those of past semesters. As might be expected, the student ratings of the course were among the highest ever.

However, the above success in the research course cannot be expected at every university. The success was not due to some unique contribution that computers add to this type of course, but rather it was due to the fact that the faculty was able to teach the research process using topics and methods that they were enthusiastic about. It just so happens that computers are necessary for the type of research that these faculty members conduct. However, it is more often the case than not that design and research courses are taught by faculty with a specialty in one of the traditionally experimental areas (e.g., learning/ memory, cognitive, and physiological)-areas in which the computer has become one of the dominant research tools. In such areas of study, computers significantly enhance the student's ability to participate in the excitement of the research experience.

\section{Conclusion}

In conclusion, several points are worth mentioning. First, it should be reiterated that the NSF College Science Instrumentation Program is an excellent source for the funding of an undergraduate psychology computer lab. The entire funding procedure is as simple and as flexible as it could possibly be; plus, the receiving of such a grant provides for a great deal of leverage within one's own institution.

I would also like to emphasize what a positive, energizing force that a computer laboratory can be for a department. All of the faculty are willingly reworking their courses to include computers (two of them have spent considerable amounts of time to construct their own software), and students are more involved in their research projects than ever before. I can think of no other change in our department that has had a more positive impact.

Finally, we still have a long way to go before we completely integrate computers into our program. Most of the evaluations done to this point have been rather informal. More formal evaluations are certain to uncover many more problem areas than those we have found thus far. Ideally, it might be desirable to move slowly towards implementation as suggested by Butler (1986). However, to demonstrate to our university and to NSF that their funds were being well spent, we opted for a very rapid implementation. I am certain that, by moving towards implementation as rapidly as we have, mistakes have been made that could have been avoided. For example, we discovered, just as Hornby and Anderson (1988) did, that the simulation experiments in Simlabs and Discovering Psychology need supplemental worksheets to tie in the lab experience with the material covered in class. However, Hornby and Anderson made this discovery with one small section of introductory students, whereas we made the discovery with 700 introductory students. Ob- 
viously, from a teaching standpoint, their approach was preferable. However, the problems that we have encountered have not dimmed our enthusiasm for the importance of the computer in teaching research to undergraduates.

\section{REFERENCES}

BUTLER, D. L. (1986). Integrating statistical software into laboratories and laboratory courses. Behavior Research Methods, Instruments, \& Computers, 18, 241-244.

CAstellan, N. J., JR. (1984). A model for courseware development in psychology. Behavior Research Methods, Instruments, \& Computers, 16, 165-167.
Castellan, N. J., JR. (1986). Issues in the effective use of computers in introductory and advanced courses in psychology. Behavior Research Methods, Instruments, \& Computers, 18, 251-256.

EAMON, D. B. (1986). Integrating a computer component into the student psychology laboratory: Problems and prospects. Behavior Research Methods, Instruments, \& Computers, 18, 245-250.

HoRNBY, P., \& ANDERSON, M. (1988). Using computers in introductory psychology. Behavior Research Methods, Instrumentation, \& Computers, 20, 180-183.

Levy, C. M., Grant, J. L., Morgan, M. D., \& Yunker, E. (1985). Discovering psychology [Computer program]. Bayport, NY: Life Science Associates.

Queen's University Psychology Department. (1986). Simlabs [Computer program]. Mishawaka, IN: Soft Productions. 